\title{
Nature of Occupational Incidents among Electrical Contractors
}

\author{
Pouya Gholizadeh, Ph.D. Candidate ${ }^{1}$ and Behzad Esmaeili, Ph.D. ${ }^{2 *}$ \\ 1 Graduate Research Assistant, Sid and Reva Dewberry Department of Civil, Environmental and Infrastructure \\ Engineering, Volgenau School of Engineering, George Mason University, 4400 University Drive, MS 6C1, Fairfax, \\ Virginia 22030; PH: (402) 417-3128; e-mail: pgholiz@masonlive.gmu.edu \\ 2 Assistant Professor, Sid and Reva Dewberry Department of Civil, Environmental and Infrastructure Engineering, \\ Volgenau School of Engineering, George Mason University, 4400 University Drive, MS 6C1, Fairfax, Virginia \\ 22030; PH: (703) 993-3688 e-mail: besmaeil@gmu.edu \\ * Correspondence: besmaeil@gmu.edu; Tel.: +1-703-993-3688
}

\begin{abstract}
Electrical contractors have experienced a rise in occupational fatalities in recent years. In 2017, electrical contractors also had the second highest number of non-fatal injuries among specialty trade contractors. Identifying statistically significant dependencies between these catastrophic outcomes and a handful of well-defined contributing factors in construction accidents offers a first step in mitigating the risks of construction accidents in this trade. Therefore, this study used methodologies of descriptive and quantitative statistics to identify the contributing factors most affecting occupational accident outcomes among electrical contracting enterprises, given an accident occurred. Accident reports were collected from the Occupational Safety and Health Administration's fatality and catastrophe database. To ensure the reliability of the data, the team manually codified more than 600 incidents through a comprehensive content analysis using injury-classification standards. Inclusive of both fatal and non-fatal injuries, the results showed that most accidents happened in nonresidential buildings, new construction, and small projects (i.e., $\$ 50,000$ or less). The main source of injuries manifested in parts and materials (46\%), followed by tools, instruments, and equipment (19\%), and structure and surfaces (16\%). The most frequent types of injuries were fractures $(31 \%)$, electrocutions $(27 \%)$, and electrical burns (14\%); the main injured body parts were upper extremities (25\%), head (23\%), and body system (18\%). Among non-fatal cases, falls (37\%), exposure to electricity (36\%), and contact with objects (19\%) caused most injuries; among fatal cases, exposure to electricity was the leading cause of death (50\%), followed by falls (28\%) and contact with objects (19\%). The analysis also investigated the impact of several accident factors on the degree of injuries and found significant effects from such factors such as project type, source of injury, cause of injuries, injured part of body, nature of injury, and event type. In other words, the statistical probability of a fatal accident-given an accident occurrence-changes significantly based on the degree of these factors. Beyond these outcomes, the described content-analysis methodology contributes to the accident-analysis body of knowledge by providing a framework for codifying data from accident reports to facilitate future analysis and modeling attempts (e.g., developing logistic regression models) to subsequently mitigate more injuries in other fields.
\end{abstract}

Keywords: Safety; Electrical contractors; Construction accidents; Nature and outcome of injuries; Chisquare test of independence 


\section{Introduction}

Preventing occupational incidents in the construction industry is challenging, since this industry involves a large number of relatively small employers, multi-employer worksites, numerous hazards, and a highly mobile workforce [1-3]. The risk of injury for construction workers especially escalates when these workers frequently interact with electricity, as is the case for electrical contractors: An examination of the National Traumatic Occupational Fatalities (NTOF) database revealed that, although construction laborers have the highest number of fatalities among the 38 different occupations included in the database, electrical power installers and repairers have the highest rate of fatalities among all occupations [4].

Many of these risks manifest in the nature of the work - electrical contractors' job entails installing and maintaining electrical systems as well as using a variety of hand tools (e.g., screwdrivers, pliers, knives, and hacksaws), power tools, and testing equipment [1]. Complicating the occupational safety of this entire population is the fact that, because of the degree of skill required, electricians often spend most of their career in one of two categories [1,5]: indoor contractors, who install conduits, connect wires, test circuits, and install and maintain lighting systems; and outdoor contractors, who work with high voltage wiring in settings ranging from the community to the consumer. Problematically, unlike other specialty trades, who have experienced a decreasing number of injuries and fatalities in recent years, the number of fatal injuries across electrical contractors has increased rapidly between 2011 to 2016 [6].

To better understand the nature of these occupational incidents among electrical contractors - and therefore to discover effective safety interventions to prevent injuries, especially fatalities - this study analyzed a large national database of occupational accidents to detect which statistically significant influential factors contribute to injuries and deaths among electrical contractors. Due to the categorical nature of accident factors (e.g., sources of injuries, event type), determining the correct values for these factors remains one of the main challenges of using historical accident data. Therefore, this study adopted a rigorous content-analysis method to ensure the reliability of final variables. The effects of influential accident factors on the fatality rates were then analyzed using the chi-square test of independence. Given the statistical significance of the variables identified during this study, these results will help practitioners to better understand nature of accidents, design specialized training programs, consider safety during design, choose alternative means and methods of construction, identify high-risk periods of a project, help small contractors better allocate their resources, and more strategically select injury-prevention practices.

The research team conducted an in-depth literature review related to occupational incidents among electrical contractors. Since electrical contractors are extensively exposed to electrical hazards, the research team also reviewed existing studies to better understand how workers get involved in electrical accidents. Salient results of the literature review are provided here.

\section{Background}

\subsection{Occupational Incidents Among Electrical Contractors}

Studies that have investigated the nature of accidents among electrical contractors are minimal. In a 2003 study, Abudayyeh et al. [1] developed a survey based on the Bureau of Labor Statistics (BLS) safety and health statistics database to identify tasks associated with injury, illness, and fatality trends in electrical contracting. Their study revealed information on important factors contributing to (mostly non-fatal) injuries - such as sources of injuries, event types, and nature of injuries - that occurred to electrical workers between 1992 to 1998. While the results were of interest to the current study, their study faced several limitations: (1) results were based on perceptions of contractors who responded to survey and not their actual incident history; (2) geographical distribution of respondents was limited to Michigan; and (3) sample size was very small-only ten contractors responded to the survey. However, comparing the 
magnitude of attributing factors in their study to more recent accident data could provide perceptive discussion on accident mechanisms among electrical workers.

To investigate nature and impact of burn-related injuries on electrical utility workers, Fordyce et al. [7] reviewed 872 reports from the Electric Power Research Institute database between 1995 and 2004. The results indicated that while the numbers of burn-related accidents (including thermal, electrical, and chemical burns) were not high, such injuries resulted in a higher number of work days lost and more serious injuries compared to other injury types. Although burn-related injuries accounted for just $3.7 \%$ of all injuries, they seemed to be costlier, representing about $13 \%$ of all medical costs.

Some studies supported by the Electric Power Research Institute (EPRI) focused on the safety and health of electric utility and power industry workers. For example, Fordyce et al. [8] analyzed neck injuries among electric utility workers from 1995 to 2007 and found higher rates of neck injuries in young males who had trade/craft worker experience. In another study, Fordyce et al. [9] investigated fatal and non-fatal injuries and injury-severity factors among electric power industry workers between 1995 and 2013 and found that fatal injuries were most commonly associated with vehicle collisions and contact with electric current. They also found risk of fatalities to be higher among line workers and that line workers experienced the second highest risk for non-fatal severe injuries, after meter readers. More recently, Volberg et al. [10] analyzed the EPRI occupational health and safety database to study injuries among electric power industry workers from 1995 to 2013. They found that while injury rates among electric power industry workers tended to decrease over the study period, rate of injuries remained high among certain high-risk workers: line workers, mechanics, young males, older welders and machinists, and female meter readers. Though each of these studies contributed to the overall body of knowledge, one limitation these studies shared was that their database only included EPRI member companies (i.e., 18 large electric power companies) and only covered a few occupations, both of which indicate that there may be selection bias in results.

\subsection{Electrical Incidents on the Whole}

Contact with electric current is a major cause of injury and death among construction workers [11-18]. Between 1994-2000, Census of Fatal Occupational Injuries (CFOI) data indicated that "contact with electric current" was the fourth leading cause of work-related deaths - after "falls," "transportation incidents," and "contact with objects and equipment" (McCann et al. 2003). Finding innovative ways to identify, assess, and mitigate electrocution hazards in the early stages of a project would save lives and prevent injuries.

Most studies investigating electrocution accidents have relied on reviews of accident reports. Jenkins et al. [19] investigated all fatal occupational injuries in the U.S. from 1980 to 1989. Electrocution was reported to be the fifth most frequent cause of occupational deaths in all industries in the U.S. (responsible for $7 \%$ of all deaths); however, in the construction industry, electrocution accounted for more than $15 \%$ of fatalities, making electrocution the industry's second most frequent cause of death after falling. Furthermore, the construction industry was the only industry for which electrocution was one of the top three causes of fatalities, and about $39 \%$ of all fatal electrocutions happened in the construction industry. According to Cawley and Homce [20], electricians and their apprentices, followed by construction laborers and electrical power installers, were the most vulnerable groups to electrical fatal injuries.

McCann et al. [16] studied construction fatalities between 1992 and 1998 using the CFOI database and injury reports. Categorizing workers into electrical and non-electrical trades, they conducted several statistical analyses to find significant differences between these groups. The results revealed that working on or near "live" electric current is a major cause of injury and death among electrical accidents. To reduce the risk of these kinds of accidents, they suggested a permission process for people working on live circuits, along with use of personal locks and training sessions. The 61 non-fatal electrical injuries detailed in this 
study were limited to one hospital and therefore might not reveal common sources of injuries for electrical contractor's trade.

In another study, Janicak [17] analyzed CFOI data from 2003 to 2006 to identify influential variables involving electric current. He found that contact with overhead power lines was the most common injury event in both the construction industry $(47.2 \%)$ and all other industries $(43.2 \%)$. Other frequent electrocution events in the construction industry that caused fatalities included contact with wiring, transformers, or other electrical components (34.3\%); and contact with the electric current of machines, tools, appliances, or light fixtures $(12.4 \%)$. These were followed by some minor causes, including contact with electric current, unspecified (2.6\%); struck by lightning (2.4\%); and contact with underground, buried power lines (1.0\%). Janicak [17] also calculated proportionate mortality ratios (PMRs) and found that the construction industry had $20 \%$ more fatalities due to contact with wiring, transformers, or other electrical components than was expected statistically. The study concluded that contact with wiring, transformers, and other electrical components contributed to a higher proportion of fatalities in the construction industry compared to other industries. Notably, Janicak's study focused on fatal injuries and did not consider nonfatal scenarios, which are more prevalent among electrical workers.

In an attempt to develop a coding system that would facilitate the categorization of fatal electrocutions and selection of prevention strategies, Chi et al. [21] examined 255 occupational electrical deaths from 1996 to 2002. They considered variables such as the cause of electrocution, performing task, source of injury, individual factors, and company size, and identified five main accident patterns for electrocution accidents: direct worker contact with an energized power line; boomed vehicle contact with an energized power line; conductive equipment contact with an energized power line; direct worker contact with energized equipment; and improperly installed or damaged equipment. The results of this study could help practitioners determine electrocution protection strategies according to specific characteristics related to accident patterns and variables that impact potential risk factors.

To create a safer environment near dangerous zones of power lines, Hesla [22] analyzed the underlying reasons for accidents near energized power lines and found the main contributors to be distraction of crane operators and observers, unclear working zones, and inability of workers to indicate the location of power lines. To mitigate risk of such accidents, he suggested providing appropriate equipment, such as line guards, ball markers, cone shaped markers, and line conductor coils. Other researchers developed wearable electric field sensors to notify workers or their supervisors when a worker comes in proximity to, or in contact with, a live power circuit. In addition, anti-current devices that prevent transmission of electrical current from energized power lines to vehicle components [23] can be used to reduce risk of contact between a boomed vehicle and overhead power line. Alternatively, proximity and current warning devices can notify at-risk workers or operators to avoid potential contact instead of interrupting the transmission of electricity.

As mentioned earlier, these studies focus only on electrical hazards and do not study other types of incidents (e.g., falls) in which electrical contractors may also be involved. Moreover, the data for these studies were usually collected from all trades within the construction industry (e.g., large building construction and heavy civil companies), and therefore their findings might not be pertinent to small specialty (i.e., electrical) contractors. While results of these studies can help to reduce electrocution, to be effective, safety programs need to be designed and implemented for specific trades and based on characteristics of certain tasks and sequences. Therefore, there is a need to study accident patterns among electrical contractors.

\section{Point of Departure}

The results of the literature review indicated four limitations in previous studies related to the occupational health and safety of electrical contractors: (1) some studies focused only on fatalities and 
ignored other incident outcomes; (2) most of the studies investigated electrical incidents, with only a limited number of studies examining via a large database documented incidents among electrical contractors industry-wide; (3) most of these previous studies only reported descriptive data without using any inferential statistics; and (4) not all of accident types that can happen to electrical workers have been investigated in previous studies.

To address these limitations, researchers need to analyze more recent incident report databases and employ more sophisticated statistical techniques to make inferences that can help practitioners better understand the nature of incidents among electrical contractors and mitigate the risk of injuries and fatalities [24]. Therefore, this study has collected data from the Occupational Safety and Health Administration's (OSHA's) Integrated Management Information System (IMIS) accidents database to analyze accidents related to electrical contractors using a chi-square independence test. One advantage of using OSHA reports in this study is that the reported values for accident factors have been checked and modified based on available summaries, which serves as a major step in understanding the true mechanisms of electrical accidents. We will detail our approach in the methodology section that follows.

\section{Methodology}

To attain this study's research objectives, the analysis first requires reliable national data of incidents among electrical contractors. Consequently, the authors acquired data from OSHA and then conducted a thorough content analysis to (1) ensure the consistency of variables across the data, (2) reduce the ambiguity of reported values, and (3) prepare the data for statistical analysis. Previous studies have successfully used this approach to analyze construction accident databases [24-28]. To investigate and explain the relationship between contributing factors to accidents and the degree of accident injuries, chi-square and Cramer's V tests were applied. The rest of this section has been devoted to explaining each of these steps.

\subsection{Incident Database}

Using the OSHA IMIS online database, the authors collected 621 accident reports about injuries involving electrical contractors between 2007 to 2013. While most of these accidents only involved one worker, some cases included multiple injuries; thus, in total, 689 electrical workers' occupational injuries were entered into the database during the seven-year period of this study. One should note that OSHA only requires documentation of 'catastrophic' accidents, wherein a work-related accident caused a fatality, in-patient hospitalization, amputation, or loss of an eye. Therefore, most of the reported accidents had serious outcomes, and only a small fraction of reports included non-hospitalized injuries. Other than nonhospitalized amputations/loss of an eye (which still need reporting), two reasons for the presence of nonhospitalized cases in data include: i) accident affected multiple employees and therefore was reported because some injuries were fatal or needed hospitalization, and ii) employer reported incident even without being required by law. It is also important to note that inclusion in OSHA's database inherently means an accident occurred. Thus, studying this database enables researchers to assess accidents that occurred historically rather assess or predict rates of accidents, which would require data outside the scope of this study.

Within each entry in the large database appears a summary of each accident, as reported by OSHA inspectors, and a limited number of variables used to describe the accident (e.g., event type, source, and cause of injury), its context (e.g., project end-use, type, cost), and its consequences (e.g., nature and degree of injuries, injured part of body). While these reports provide good information about accident causes and outcomes and help researchers to understand how these catastrophic incidents occurred, the authors detected several constraints that needed to be addressed before data were ready for analysis. These efforts are summarized in data preprocessing section. 


\subsection{Data Preprocessing: Issues with the Reported Variables}

OSHA's documentation of accidents involving electrical workers started in 1995, with more frequent reports appearing after 2002. The database's public availability, along with its level of detail, have made it one of the most reliable sources of information in many safety-related studies [29-31]. In particular, the cases' concise descriptive titles, short summaries, and many included categorical variables provide a robust amount of information for researchers seeking to grasp accident situations or build statistical analyses.

However, like any other source, there are some deficiencies in the OSHA IMIS database that need to be addressed before conducting any valid analysis on the data. More specifically, the research team identified four main issues with data: (1) non-work related incidents and cases with insufficient information; (2) missing/ambiguous values; (3) misclassified variables; and (4) variables with too many categories. The data-processing activities implemented for each issue are describe here.

\subsubsection{Non-work related incidents and cases with insufficient information}

Five reports mentioned no injuries and one report corresponded to a trade other than electrical contractors. Additionally, in 17 cases, main cause of injury was not work-related. These included instances of heart attack, embolism, and seizure. For instance, one inspection reports:

- $\quad$ Report\# 200923076: “... Employee \#1, with [name of the company], was installing an underground power line to a new house under construction. He wasn't feel[ing] well, and he went to the truck and collapsed. He was taken to the hospital, where he died later that same day at approximately 4:30 p.m. Employee \#1 suffered from Atherosclerotic Cardiac Vascular Disease, and it appears that this was his cause of death."

Another 47 cases were reviewed but were found to have insufficient information to be included in the analysis - no specific values were reported for any variable in these cases. For instance, "On October 9, 2012, Employee \#1 was found in the master bathroom on the second floor with injuries to the forehead and right eye. Employee \#1 did not remember falling or hitting his head or working off a ladder."

In total, 70 cases were omitted from further investigation, leaving 619 incidents for analysis.

\subsubsection{Missing/ambiguous values}

While excluding 70 accidents in the first step removed almost all the missing values from the main variables of the study, a large number of accidents were still reported with variables that were assigned to the "other" category. Variables such as "sources of injuries", "event type", and "nature of injuries" had, respectively, 56, 91, and 57 incidents with "other" values. To modify these ambiguous situations, this study adopted categories found in the Occupational Injury and Illness Classification Manual (OIICM), developed by the U.S. Department of Labor Bureau of Labor Statistics [32]. OIICM “provides a classification system for use in coding the case characteristics of injuries, illnesses, and fatalities in the Survey of Occupational Injuries and Illnesses (SOII) and the CFOI programs" [32, p. 4]. The manual also provides examples and guidelines on selecting the right division or subdivision within each variable.

Using OIICM, the research team could find correct values for most of these cases. For instance, in the following report, three variables were reported as "other":

- Report\# 200203305: “... While installing the transformer, Employee \#1 was sitting on top of the transformer conducting a standard Doble test (10 Kv) with a M4100 instrument testing the H2 arrestor, when he was electrocuted..." 
However, one can assign "electrocution" to the nature of injury, "electric parts" to the source of injury, and "exposure to electricity" to the event type using the OIICM rules. Consequently, the research team applied this codifying procedure to cases wherein variables had been left ambiguous.

\subsubsection{Misclassified variables}

One limitation of OSHA's accident reports lies in their subjective nature. Several categorical variables are identified and reported in these reports, including source of injuries, event type, nature of injuries and part of body. However, sometimes it is not clear which values should be assigned to these variables and two inspectors, visiting the same accident site, can report events differently. An example could clarify this issue:

- Report\# 201562329: “... Employee \#1 was working above a false ceiling at the height of about $19 \mathrm{ft}$. He was standing on a 20-ft extension ladder. At some point, Employee \#1 fell from the ladder from over $8 \mathrm{ft}$ through the false ceiling and struck his head against the concrete floor..."

- $\quad$ Report 201187010: “... Around 1:30 p.m., Employee \#1 began climbing the fixed ladder to access the roof. While transferring from the ladder to the roof, he lost his balance and fell approximately $17 \mathrm{ft}$ from the roof. He struck his head on the concrete surface, sustaining severe head trauma..."

Both reports describe very similar situations in which a worker lost his balance, fell from a ladder, and hit the ground. However, in the first case, source of injury was reported as a "working surface" and for the second, a "ladder". While both sources might be deemed as valid choices, it is not possible to analyze data with these inconsistencies.

To create consistency among similar cases, the research team used OIICM to identify the closest category to the source (mentioned in the text of the report). For instance, in one report (i.e., 170390918), an employee was struck by a rough-terrain forklift. The source was reported as "material handling equipment" by OSHA. However, searching through OIICM shows that forklifts should be classified as "industrial vehicles, material hauling and transport-powered" and are therefore a type of vehicle and not an equipment. Due to the importance of having a consistent interpretation of accidents, the research team manually reviewed all accident summaries and designated correct values for the four variables mentioned above.

\subsubsection{Variables with too many categories}

Another issue with the data appeared in that for some categorical variables there were limited numbers of observations which diminishes their power in the statistical analysis methods. For instance, there were 27 parts of body identified in accident reports, with some body parts logging only a few occurrences. To address this challenge, the authors decided to combine some categories based on available standards and manuals to prepare data for more advanced analysis methods.

Other than OIICM - which is helpful for four accident-factor variables - this study utilized the "North American Industry Classification System (NAICS)," which was developed collaboratively by the Instituto Nacional de Estadística y Geografía (INEGI) of Mexico, by Statistics Canada, and by the United States Office of Management and Budget [33]; NAICS defined end-uses of projects and provided a standard method to define construction projects.

\subsection{Data Preprocessing: Reclassifying Influential Variables}


The rest of this section provides details regarding the content-analysis process as well as final identified levels for these five accident factors: end-use, nature of injury, part of body, source of injury, and event type.

\subsubsection{End-use}

Initially, 17 end-uses were included in the data, with some end-uses-i.e., shoreline development, dam, reservoir; pipeline; and bridge-including only one incident. From these 17 categories, two remained unchanged (i.e., commercial buildings and other buildings), whereas one category (i.e., "Contractor's yard/facility") featured six instances that the research team recategorized to match NAICS designations: four instances were moved into commercial buildings, one moved to residential, and one moved to power-and communication-line and related structures. The remaining end-uses have been combined to create five meaningful categories using NAICS. These five categories and their sub-categories appear in Table 1. As one can see, in some cases, only the names were modified slightly to match with the standard while others were reclassified completely.

Table 1 - Reclassifying end-uses

\begin{tabular}{ll}
\hline Category & Sub-category (frequency) \\
\hline Residential building & Multi-family dwelling (23); Single family or duplex dwelling (44) \\
Nonresidential building & Commercial building (234); Industrial building (manufacturing plant) \\
& (44); Other building (128) \\
Highway, street, and bridge & $\begin{array}{l}\text { Bridge (1); Highway, road, street (27); } \\
\text { Utility system }\end{array}$ \\
& $\begin{array}{l}\text { Oil and gas pipeline and related structures (16: including 1 Pipeline, } 12 \\
\text { Tower, tank, storage elevator, and 3 Refinery); Power and } \\
\text { communication line and related structures (i.e., Powerline, } \\
\text { transmission line, 69); Water and sewer line and related structures (i.e., }\end{array}$ \\
& Sewer/water treatment plant, 5) \\
Other heavy and civil & Excavation, landfill (2); Other heavy construction (7); Powerplant (18); \\
engineering & Shoreline development, dam, reservoir (1) \\
\hline
\end{tabular}

\subsubsection{Nature of injuries}

In the first round, the authors only adjusted injury naming conventions based on OIICM. For instance, "electric shock" changed to electrocutions, electric shocks. Thereafter, cases of "burns" were studied carefully to distinguish between electrical burns and thermal burns; this step was important as in the electrical trade, most burns were due to electrocutions, so using a general term would be misleading. Third, the "other" cases were reviewed in an attempt to designate better definitions. For example, in report \#201187010, the employee "struck his head on the concrete surface, sustaining severe head trauma"; while the nature was reported as "other," the research team concluded that this case could be designated as concussion.

This categorizing process resulted in 16 injury categories of OIICM (except for 35 non-specified cases). Eight categories had frequencies of fewer than 10 cases: "asphyxiations" (9); "thermal burns" (8); "effects of heat and light" (5); "multiple traumatic injuries and disorders" (3); "puncture wounds" (3); "sprains, strains, and tears" (3); "hernias" (1); and "internal injuries to organs and blood vessels of the trunk" (1). To reduce the number of categories, these small groups were reclassified for this study as other and created the final 9 categories (Table 4).

\subsubsection{Part of body}


Next, the authors investigated which part of body had been injured in accidents. Here, the concern was less about subjective judgments and more about high number of categories (i.e., 26). Initially, 14 cases featured missing data, which the research team reviewed; except for one case (i.e., a worker was struck by a socket on his back: classified as trunk), all these cases were reclassified as body system, as they involved serious electrocutions, falls, or heat exhaustions in which the whole body was affected. Table 2 shows how this study combined the remaining 25 categories into six groups. The only modification from OIICM is that, the authors have added the "neck" category to "head" as there were only six cases of injured necks in data.

Table 2 - Reclassifying injured parts of body

\begin{tabular}{ll}
\hline Category & Sub-category (frequency) \\
\hline Head & Ears (1); Eyes (2); Face (26); Head (106); Neck (6) \\
Upper extremities & Arm-multiple (40); Elbows (1); Fingers (37); Hands (69); Shoulder (5); Upper Arm \\
& (1); Wrists (3) \\
Trunk & Abdomen (8); Back (19); Chest (36); Hips (9); Kidney (1); Lung (2); \\
Lower extremities & Foot/Ankle (29); Knees (2); Legs (25); Lower leg (3); Upper leg (1) \\
Multiple body parts & Multiple body parts (78) \\
Body system & Body system (109) \\
\hline
\end{tabular}

\subsubsection{Sources of injuries}

Investigating sources of injuries was the most challenging task during data preprocessing, which further demonstrated the need to follow a uniform standard and train OSHA inspectors in their coding. In addition to small renaming step for the 35 original categories, the research team ended up reviewing most of the reports, which ultimately resulted in changing the designated sources for more than 200 cases. We have provided some examples here to further highlight the need for conducting such thorough content analysis and reclassification.

Consider the following incident:

- $\quad$ Report\# 202479499 “... Employee \#1 removed a light bulb and cut wires while he was standing on the ladder. Employee \#1 grabbed the top of a light fixture with his left hand and was trying to remove a bolt with pliers, when he felt an electric shock. This caused Employee \#1 to fall from the ladder and he landed on the concrete floor below ... sustained hip fracture and scalp laceration in the event..."

One could list three potential sources for this case: electric part, ladder, or floor. OSHA has considered electric part as the main source. However, the main event that led to injury - as mentioned in the reportwas "fall to a lower level." OIICM guidance explains that in these events, "name the equipment or part of the structure (structural element) from or through which the worker fell" as the source and "name the object or substance, if any, that contributed to the worker's fall" as the secondary source [32, p. 110]. By this definition, ladder and electric parts would be the source and the secondary source, respectively. Seven cases were modified similarly.

Another common confusion manifests when the worker was electrocuted indirectly through some objects other than the source of electricity:

- $\quad$ Report\# 200360089 “... He was electrocuted when he touched an aerial lift truck that had become energized when it was mistakenly grounded to an energized conductor ..." 
OSHA inspectors often listed the electric part as the source while OIICM clearly discussed similar situations and pointed out that the object (in this case the aerial lift truck which is a highway vehicle, motorized) is the source, whereas the electric part should be considered the secondary source [32, p. 111].

In some other reports, the sources were incorrectly reported. In one case, for instance, an employee simply fell from a lift truck, but the source was reported as "electric part" for no obvious reason. In total, 20 cases of "electric parts" were changed during this data-processing task.

There were 15 cases in which the source was reported inaccurately as "material and personnel handling machinery." Only one of these cases is presented here, where the source should have been roof, as the location designates from where the worker fell:

- $\quad$ Report\# 202588901 “... As he walked in that direction, he slipped on the icy roof. He fell approximately 12 feet onto another roof below and then an additional 12 feet to the grade below..."

The research team also applied additional attention to 60 cases of "other" sources. All these cases were reviewed and modified to clarify the sources. The following is an example of 18 similar cases were reassigned to be structures other than buildings:

- $\quad$ Report\# 202457560 “... Employee \#1 used his climbing gaffs to climb the telephone pole to the height necessary to install the telecommunication cable... As Employee \#1 was placing the belt under the plastic conduit, his improperly maintained climbing gaff broke out, and he fell approximately 25 feet..."

As the worker fell from a pole, this type of event should have been classified under structures other than buildings via the OIICM standard. One might note that at this step, some of the sources that were found from reports may be in level 3 or 4 of the manual (i.e., more detailed definitions). For instance, roof was a level 3 source (i.e., 654) under a broader level of other structural elements (i.e., 65), which itself is classified under division 6: structures and surfaces. To reduce the number of categories and summarize data, the research team decided to use the more general (i.e., one-digit) ontology level for source of injury. Table 3 shows this transition and the final six categories.

\subsubsection{Event type}

The last variable that was investigated through the lens of OIICM was event or exposure type. The manual defined this variable as: "the manner in which the injury or illness was produced or inflicted by the source of injury or illness" [32, p. 274]. As mentioned before, all "other" cases were reviewed and replaced with new categories. For instance, the following case was reclassified as exposure to electricity:

- Report\# 202601019 "... After he untied three loosely-hanging cables from the panel's "on/ off" control handle, the cables fell downward, contacting exposed, energized bus bars. An arc flash then occurred. Employee \#1 was hospitalized for burns on his face, hands and upper body ..."

Beside the other cases, in general, this event type variable was reported accurately, though 20 cases (mostly reported as "struck-by") were changed to exposure to electricity after a careful review. As mentioned in the next example, most such cases involved an arc flash, which does not meet the criteria for a struck by accident:

- Report\#202522926 “... Employee \#1 of (name of company) was using a power tool to remove a breaker in a live electrical panel when the tool grounded and resulted in an arc flash..." 
Table 3 - Reclassifying sources of injuries

\begin{tabular}{ll}
\hline Category & Sub-category (frequency) \\
\hline Machinery & Agricultural and garden machinery (1); Construction, logging, and mining \\
& machinery (4); Heating, cooling, and cleaning machinery and appliances (1); \\
& Material and personnel handling machinery (38); Metal, woodworking, and \\
& special material machinery (1) \\
Parts and materials & Building materials - solid elements (14); Containers (1); Electric parts (256); \\
& Fasteners, connectors, ropes, ties (2); Furniture and fixtures (1); Hoisting \\
& accessories (5); Machine and appliance parts (1); Metal materials-nonstructural \\
& (1); Other parts and materials (2); Parts and materials, unspecified (1); Vehicle \\
& and mobile equipment parts (2) \\
Buildings - office, plant, residential (1); Confined spaces (7); Floors, walkways, \\
ground surfaces (10); Other structural elements (24); Structures other than \\
surfaces \\
buildings (55) \\
Tools, instruments, \\
Hand tools - nonpowered (3); Hand tools - powered (12); Ladder (102); Other \\
tools, instruments, and equipment (1) \\
Vehicles \\
$\begin{array}{l}\text { Highway vehicles motorized (37); Off-road and industrial vehicles - powered } \\
\text { (12); Plant and industrial vehicles - nonpowered (1) }\end{array}$ \\
Chemical products - general (1); Coal, natural gas, petroleum fuels and \\
products (1); Containers (4); Environmental and elemental conditions (11); \\
Other chemicals (2); Other steam, vapors, liquids, ice (3); Person - injured or ill \\
worker (1)
\end{tabular}

OIICM explicitly classifies "arc flash" as a direct form of exposure to electricity alongside other events such as direct contact with powerlines.

After the first phase, 11 events and exposures were identified, with seven events with low frequencies [i.e., "explosions" (6); "exposure to other harmful substances" (5); "exposure to temperature extremes" (7); "falls on same level" (8); "fires" (2); "struck against object or equipment" (9); and "struck, caught, or crushed in collapsing structure, equipment, or material" (3)] collapsed into the other category creating final five event type categories.

\subsection{Analysis Methodologies: Pearson Chi-Square Test of Independence and Cramer's V}

When variables of the study are nominal, chi-square test can be used to determine significant associations among any pair of variables by calculating a test statistic (i.e., $\chi^{2}$ ), which approaches a chisquare distribution [34]. Researchers have used this test for more than 100 years [35]: in psychology studies that were published in six journals in 2008 alone, the results of the chi-square test were reported more than 600 times [36]. In construction research, Mustapha and Naoum [37] have utilized this test to show that the effectiveness of construction managers is related to their age, university degree, membership in professional institutes, overseas experience, and management style. Zuppa et al. [38] have performed chisquare tests on survey data and found that building information modeling have strong positive impact on projects' success measures such as quality, cost, and schedule. Similar to these efforts, this study has adopted chi-square test of independence to identify accident factors with significant effect on the degree of an injury. Consider a contingency table with R rows, $\mathrm{C}$ columns and c cells, the test statistic is:

$$
\chi 2=\sum_{r=1}^{c} \frac{\left(O_{r}-E_{r}\right)^{2}}{E_{r}}
$$

Where $\mathrm{O}_{\mathrm{r}}$ is the number of observations in cell $\mathrm{r}$ and $\mathrm{E}_{\mathrm{r}}$ is the expected count in cell $\mathrm{r}$ : 


$$
E_{r}=\frac{M_{R} \times M_{C}}{N}
$$

Where $\mathrm{N}$ is the total number of observations, $\mathrm{M}_{\mathrm{R}}$ is the row marginal for cell $\mathrm{r}$, and $\mathrm{Mc}$ is the column marginal for that cell. Once the test statistic is known, it can be compared to a chi-square distribution with $(\mathrm{R}-1) \times(\mathrm{C}-1)$ degrees of freedom to acquire the p-value. A small $\mathrm{p}$-value can reject the null hypothesis that the variables are independent.

To evaluate the strength of significant associations, chi-square tests usually are accompanied by the simple and widely used Cramer's V [34,39] test introduced by Cramer [40]:

$$
V=\sqrt{\frac{\chi 2}{N[\min (R, C)-1]}}
$$

Higher values of $V$ indicate a stronger association among two variables. Using Phi coefficient (i.e., Cramer's V with the sign of the effect), one can also measure the effects at each level of significant factors [41]. The effects of several contributing accident factors on the degree of injury would be tested through these three test statistics.

\section{Results}

The results are presented in two separate sections. First, the explanatory statistics of catastrophic accidents that have affected electrical contractors from 2007 to 2013 are presented. The emphasis is on the degree of injury as the most evident outcome of these incidents. Then, the associations between degree of injury and several variables - such as type of projects (i.e., project end-use, type, and cost), worker's task (i.e., source and cause of injuries), and other outcomes of an accident (i.e., nature of injury, injured part of body, and event type)-are tested.

\subsection{Exploratory Analysis}

Within the accident reports in the database, in total, 226 (37\%) of accidents resulted in a fatality. The remaining (non-fatal) injuries were filed into two categories: $343(55 \%)$ hospitalized injuries and $50(8 \%)$ non-hospitalized injuries. As mentioned in the research methods, eight variables were coded in the content analysis to better understand the nature of accidents. The salient results and the rates of 'degree of injury' for each category are presented in Table 4 . One should note that a fatality rate in this study represents a specific quantity given the occurrence of a catastrophic accident. Hence, this fatality rate is the share of fatal injuries from the total number of catastrophic injuries in the dataset and should not be confused by estimated rates that are calculated using full-time equivalent workers. In other words, a fatality rate of $37 \%$ simply means that $37 \%$ of all injury events in the data led to a death; not that $37 \%$ of electrical workers would die on the job.

As far as end-use is concerned, electrical accidents occurred mostly in building projects (77\%), with commercial buildings being the dominant end-use. In non-building projects, utility systems (particularly power and communication lines) were the primary environments. The results indicate that different environments have quite similar fatality rates.

Another variable that can describe the project condition is the project type. Project type, as opposed to end-use, implies the purpose of construction projects and not their context. The project types with the most accidents were new project or new addition (36\%), alteration or rehabilitation $(28 \%)$, and maintenance or repair (25\%). Conditional on an accident occurring within these project types, the fatality rates for these accidents were $40 \%, 40 \%$, and $35 \%$, respectively, which are all close to the total fatality rate among electrical contractors (i.e., $37 \%$ ). However, while demolitions represent only $2 \%$ of projects, their accidents' fatality rate $(58 \%)$ is much higher than other types of projects. 
Regarding project costs, a large proportion of accidents occurred during relatively small-budget projects: around $74 \%$ of projects in have budgets less than $\$ 500,000$. While most of cost categories present fatality-rates close to the average, two categories with the highest budgets show different values: projects with budgets between $\$ 5$ to $\$ 20$ million have significantly higher fatality-rates (i.e., $52 \%$ ) while projects with more than $\$ 20$ million budgets have fatality rates of $24 \%$, which is much less than the average.

The initial 35 sources of injuries were reduced to six categories to generate more meaningful categories and to facilitate future data analysis. The largest category is parts and materials, as it involves all the electrical parts. Regarding the degree, though, vehicles and machinery caused higher fatality rates, with $58 \%$ and $44 \%$ of accidents being fatal, respectively.

With regards to causes, this study excluded 130 cases for missing values, with the remainder cases reported by OSHA inspectors as originating in 34 different tasks. Table 1 presents individual categories for whichever causes represent at least $5 \%$ of the reported data (these five categories collectively cover $61 \%$ of accidents); the remaining causes were lumped into the Other category. Installing equipment (HVAC and other), interior plumbing, ducting, electrical work, and installing plumbing, lighting fixtures were three individual causes with the most frequency. However, in terms of the severity, the fencing, installing lights, signs, etc. cases represent the highest fatality rate. Also, one might notice that the severity rate of 'not reported' cases is very close to those of the Other category.

To explain the circumstances of an accident, OSHA reports the event type. From the 12 different types that were listed by OSHA, this study could scale them down to only five categories using OIICM manual. While having high proportions of exposure to electricity with high fatality rates was expected, the findings also show that fall accidents are quite prevalent among electrical contractors.

For the nature of injuries consideration, after combining various categories based on the OIICM manual, nature of injury was classified into nine categories. Among them, only 3 categories represent $72 \%$ of all injuries: fractures, electrocutions, and burns. However, in terms of the degree of the injuries, electrocutions and concussions have given rise to the most severe injuries.

OSHA inspectors reported 27 different body parts that were injured in this data set. Based on the BLS classification, the authors have classified these body parts into the six categories presented in Table 4. Upper extremities, head, and body system were the parts with the most injuries, respectively. Injuries to the body system resulted in the highest fatality rate (64\%), indicating how electricity can critically affect the whole body.

Other variables such as human and environmental factors were also reported by OSHA inspectors. Although, a large proportion of these two factors were classified under the "Other" category (i.e., 23\% of human factors and $52 \%$ of environmental factors), Table 5 reports some of the more common factors (i.e., each factor represents at least $5 \%$ of the frequency after excluding the missing cases) for each variable. The findings show that while misjudgment is by far the main human factor, problems with lockout/tagout procedures, inappropriate position for task, and neglecting necessary safety devices were more dangerous. For environmental factors, work surface and facility layout condition is the most common factor among electrical workers that leads to accidents. However, material-handling equipment or method, overhead moving- or fallingobject action, and squeeze-point action caused higher fatality rates. The variables in Table 5, though, were excluded from the following statistical analyses due to the high number of missing values. 
Table 4 - Accident characteristics among electrical contractors

\begin{tabular}{|c|c|c|c|c|c|}
\hline & \multirow[t]{2}{*}{ Variables } & \multirow[t]{2}{*}{ Frequency $(\% 1)$} & \multicolumn{3}{|c|}{ Degree of Injury (\%) } \\
\hline & & & Fatality $^{1}$ & Hospitalized & Non-Hospitalized \\
\hline \multirow[t]{5}{*}{ End-use } & Highway, street, and bridge & $28(5)$ & 39 & 57 & 4 \\
\hline & Nonresidential building & $406(66)$ & 36 & 55 & 9 \\
\hline & Other heavy and civil engineering & $28(5)$ & 39 & 57 & 4 \\
\hline & Residential building & $67(11)$ & 34 & 54 & 12 \\
\hline & Utility system & $90(15)$ & 38 & 58 & 4 \\
\hline \multirow[t]{5}{*}{ Project Type } & Alteration or rehabilitation & $173(28)$ & 40 & 52 & 8 \\
\hline & Demolition & $12(2)$ & 58 & 42 & 0 \\
\hline & Maintenance or repair & $155(25)$ & 35 & 57 & 8 \\
\hline & New project or new addition & $222(36)$ & 40 & 50 & 10 \\
\hline & Other & $57(9)$ & 14 & 83 & 4 \\
\hline \multirow[t]{7}{*}{ Project cost } & $\$ 50,000$ and less & $276(45)$ & 34 & 58 & 8 \\
\hline & $\$ 50,000-\$ 250,000$ & $115(19)$ & 39 & 56 & 5 \\
\hline & $\$ 250,000-\$ 500,000$ & $60(10)$ & 38 & 43 & 18 \\
\hline & $\$ 500,000-\$ 1,000,000$ & $45(7)$ & 38 & 56 & 7 \\
\hline & $\$ 1,000,000-\$ 5,000,000$ & $63(10)$ & 40 & 54 & 6 \\
\hline & $\$ 5,000,000-\$ 20,000,000$ & $27(4)$ & 52 & 37 & 11 \\
\hline & $\$ 20,000,000$ and more & $33(5)$ & 24 & 70 & 6 \\
\hline \multirow[t]{6}{*}{ Source of injury } & Machinery & $45(7)$ & 44 & 56 & 0 \\
\hline & Parts and materials & $286(46)$ & 39 & 52 & 9 \\
\hline & Structures and surfaces & $97(16)$ & 31 & 62 & 7 \\
\hline & Tools, instruments, and equipment & $118(19)$ & 24 & 66 & 10 \\
\hline & Vehicles & $50(8)$ & 58 & 40 & 2 \\
\hline & Other sources & $23(4)$ & 35 & 52 & 13 \\
\hline \multirow[t]{6}{*}{ Causes } & Fencing, installing lights, signs, etc. & $30(5)$ & 53 & 43 & 3 \\
\hline & $\begin{array}{l}\text { Installing equipment (HVAC and } \\
\text { other) }\end{array}$ & $121(20)$ & 40 & 55 & 6 \\
\hline & Installing plumbing, lighting fixtures & $90(15)$ & 44 & 51 & 4 \\
\hline & $\begin{array}{l}\text { Interior plumbing, ducting, electrical } \\
\text { work }\end{array}$ & $102(17)$ & 28 & 64 & 8 \\
\hline & Temporary work (building, facilities) & $35(6)$ & 43 & 43 & 14 \\
\hline & Other & $111(18)$ & 32 & 55 & 13 \\
\hline
\end{tabular}


15 of 22

\begin{tabular}{|c|c|c|c|c|c|}
\hline & Not reported & $130(21)$ & 32 & 59 & 9 \\
\hline \multirow[t]{5}{*}{ Event type } & Caught in/between & $38(6)$ & 34 & 58 & 8 \\
\hline & Exposure to electricity & $253(41)$ & 44 & 47 & 8 \\
\hline & Fall & $210(34)$ & 30 & 67 & 3 \\
\hline & Struck-by & $78(13)$ & 37 & 46 & 17 \\
\hline & Other & $40(6)$ & 23 & 63 & 15 \\
\hline \multirow[t]{9}{*}{ Nature of injury } & Amputations, avulsions, enucleations & $21(3)$ & 0 & 71 & 29 \\
\hline & Bruises, contusions & $19(3)$ & 16 & 37 & 47 \\
\hline & Concussions & $44(7)$ & 59 & 41 & 0 \\
\hline & Cuts, lacerations & $24(4)$ & 13 & 62 & 25 \\
\hline & Electrical burns & $84(14)$ & 1 & 83 & 16 \\
\hline & Electrocutions, electric shocks & $166(27)$ & 67 & 28 & 5 \\
\hline & Fractures & $193(31)$ & 20 & 78 & 2 \\
\hline & Non-specified injuries and disorders & $35(6)$ & 86 & 14 & 0 \\
\hline & Other & $33(5)$ & 39 & 49 & 12 \\
\hline \multirow{6}{*}{$\begin{array}{l}\text { Injured part of } \\
\text { body }\end{array}$} & Body system & $110(18)$ & 64 & 32 & 4 \\
\hline & Head & $141(23)$ & 45 & 48 & 7 \\
\hline & Lower extremities & $60(10)$ & 0 & 93 & 7 \\
\hline & Multiple body parts & $78(13)$ & 19 & 78 & 3 \\
\hline & Trunk & $74(12)$ & 39 & 56 & 5 \\
\hline & Upper extremities & $156(25)$ & 31 & 53 & 17 \\
\hline
\end{tabular}

${ }^{1}$ The percentages were rounded to the closest integer and some cases might not add up to $100 \%$. 
Table 5 - Frequency and fatality rate for human and environmental factors

\begin{tabular}{llcc}
\hline Main category & Subcategory & Frequency & Fatality rate (\%) \\
\hline Human factors & Misjudgment in hazardous situation & 207 & 37 \\
& Malfunction in lockout/tagout procedure & 61 & 53 \\
& Safety devices removed or used inappropriately & 39 & 39 \\
& Insufficient or lack of personal protective & 35 & 34 \\
& equipment or clothing & 34 & 35 \\
& Inappropriate equipment for operation & 26 & 42 \\
& Inappropriate position for task & 26 & 31 \\
\hline \multirow{2}{*}{ factors } & Malfunction in securing or warning operation & 125 & 30 \\
& Work surface or facility layout condition & 39 & 51 \\
& Material-handling equipment or method & 39 & 49 \\
& Overhead moving- or falling-object action & 18 & 11 \\
& Temperature tolerance & 17 & 47 \\
& Squeeze-point action & 16 & 25 \\
\hline
\end{tabular}

\subsection{Chi-Square Independence Test}

As mentioned earlier, the second objective of the study was to test whether the degree of injuries was associated with the type of projects, the worker's task, or other outcomes of an accident. Since there were few incidents with non-hospitalized injuries, this category and hospitalized injuries were combined into one "Non-fatal" category - as opposed to the "Fatal" injuries - to increase accuracy of the tests. Table 6 presents the results of the Chi-square test for eight variables.

Table 6 - Associations between degree of injury and eight accident factors

\begin{tabular}{lcccc}
\hline $\begin{array}{l}\text { Variables against } \\
\text { degree of injury }\end{array}$ & $\begin{array}{c}\text { Chi-square } \\
\text { statistic }\end{array}$ & $\begin{array}{c}\text { Degree of } \\
\text { freedom (d.f.) }\end{array}$ & p-value & Cramer's V \\
\hline Project end-use & 0.40 & 4 & 0.98 & - \\
Project type & 16.86 & 4 & 0.00 & 0.17 \\
Project cost & 6.33 & 6 & 0.39 & - \\
Sources of injury & 21.49 & 5 & 0.00 & 0.19 \\
Causes of injury & 11.89 & 5 & 0.04 & 0.14 \\
Event type & 13.90 & 4 & 0.01 & 0.15 \\
Nature of injury & 201.25 & 8 & 0.00 & 0.57 \\
Injured part of body & 87.82 & 5 & 0.00 & 0.38 \\
\hline
\end{tabular}

The p-values in Table 6 indicate that, at the significance level of 0.05 , the probability of a fatal accident differs significantly based on the type of project, sources of injury, causes of injury, type of accident, nature of injury, and injured part of body. The results, however, show a lack of evidence to claim an association between degree of injuries and end-use, nor between degree of injuries and cost of projects. The Cramer's V values show the amount of association between the significant factors and the degree of injuries. Nature of injuries and part of body have the highest association with the degree of injury. To locate the effects among these two significant factors, the values of Phi coefficients are calculated for each level of nature and body parts (Table 7). 
Table 7 - The effect of different natures of injury and parts of body on degree of injury

\begin{tabular}{llc}
\hline Variable & Level & Phi Coefficient \\
\hline Nature of injury & Amputations, avulsions, enucleations & -0.14 \\
& Bruises, contusions & -0.08 \\
& Concussions & 0.13 \\
& Cuts, lacerations & -0.10 \\
& Electrical burns & -0.30 \\
& Electrocutions, electric shocks & 0.38 \\
& Fractures & -0.22 \\
\hline Part of body & Body system & 0.27 \\
& Head & 0.10 \\
& Lower extremities & -0.25 \\
& Multiple body parts & -0.14 \\
& Trunk & 0.02 \\
& Upper extremities & -0.14 \\
\hline
\end{tabular}

The results indicate that, among types of injury, electrocutions have the highest positive correlation with the degree of injury. In other words, electrocutions can cause moderately higher fatalities than other types of injuries. Electrical burns and fractures, on the other hand, have a moderate and weak negative relationship with the degree of injury, respectively. Regarding the injured body parts, body system and lower extremities have a little positive and negative effect on fatality rates, respectively.

\section{Discussion}

This study has two main objectives: provide a framework for treating data in OSHA's database and investigate which accident factors have a statistically significant effect on the outcome of accidents (i.e., degree of injury) among electrical contractors.

To address the first objective, the authors reviewed every report manually to ensure the quality of the final data points, as the quality of data is paramount in any scientific study, without exception. By standardizing the data in accord with the steps outlined, this framework helps researchers assess accident reports in response to the four common limitations found in OSHA's database, and in turn, resolve the database's issues. The proposed methodology and solutions can consequently be adapted to any studies with the same or similar report types. The outcomes of this standardizing process significantly reduce the ambiguity found within many accident reports.

This study also discusses the contributing factors to catastrophic construction accidents among electrical contractors. To reveal nature of accidents, summary statistics of 11 variables (e.g., end-use, project type, nature of injury) were reported. As noted by Lee et al. [42], safety-risk factors in projects are determined by location, type and complexity of projects. Better understanding these influential variables will enable safety managers to strategically allocate their limited safety resources, particularly in small enterprises. As far as electrical contractors are concerned, given situations in which an accident occurred, the results show that the majority of accidents happened in nonresidential buildings (e.g., commercial, industrial), new construction, and small projects (i.e., $\$ 50,000$ or less). Historic events do not inherently predict future events, but the statistical significance of past accident factors describe conditions in which future accidents may face added risk. Therefore, contractors who are working on these projects should plan for precautionary actions and consider larger contingencies in their budgets.

The main source of injury is parts and materials (e.g., electrical parts)-representing $46 \%$ of accident sources - followed by tools, instruments, and equipment (19\%), and structure and surfaces (16\%). These findings are compatible with a study conducted by Abudayyeh et al. [1]: For non-fatal 
accidents among electrical contractors from 1992 to 1998 reported in BLS, Abudayyeh et al. found parts and materials as the most common source of injury (25\%), followed by structures and surfaces (i.e., floors, walkways, or ground surfaces $-19 \%$ ) and all other sources $(17 \%)$. In comparison with Abudayyeh and his colleagues' results, this study shows a large increase in the share of parts and materials, which may suggest the need for more training regarding electrical sources. The share of accidents sourced in tools, vehicles, and machinery has also increased by $10 \%, 4 \%$, and $3 \%$, respectively, which may indicate the growing application of new tools and machines in construction and may emphasize the need for further, task-specific safety training and planning. One other notable outcome here is that due to the application of the comprehensive content analysis in this study, the other category is much smaller here (4\%) compared to $17 \%$ in Abudayyeh et al [1]. We posit that this difference can beneficially increase our understanding of accident mechanisms.

The most frequent nature of electrical contracting injuries were fractures $(31 \%)$, electrocutions $(27 \%)$, and electrical burns (14\%). These are in contrast with the findings of Abudayyeh et al. [1], as that study reported "sprain and strains" (37\%), "all other natures" $(23 \%)$, and "cut and punctures" $(13 \%)$ as the top three injury types among electrical workers. Only three cases of "strains/sprains" were reported in OSHA database, which can be attributed to the fact that while these injuries are prevalent among construction workers [43-45], since they usually do not lead to very serious consequences - such as permanent disability or fatality - they may have not been reported to OSHA inspectors. Indeed, this study's findings relate to more severe injury types that might otherwise be neglected or washed out due to their relatively low frequency. Such a nuance demonstrates the benefit of focusing this study on the accidents within OSHA's catastrophic database.

Considering body parts, the OSHA accident reports have upper extremities (25\%), head (23\%), and body system (18\%) as the main injured body parts. Also, lower extremities and trunk were the two parts with the lowest frequency. Regarding severity, the chance of fatality is higher when the body system or head are injured. Further investigation showed that, most of the incidents in which the whole body was affected were cases of exposure to electricity. It's important to note that the electricity usually enters from upper extremities (e.g., fingers, hands) and, most of the time, it's only the magnitude of flow which differentiates between a small injury in upper extremities and a serious (usually fatal) injury in body system. In other words, injuries to upper extremities must be analyzed more carefully, especially among electrical contractors, as they can rapidly escalate to situations in which the whole body can be severely affected.

When considering only non-fatal accidents, Abudayyeh et al. [1] reported that "contact with objects" (including struck-by and caught in/between), "overexertion," and "falls" are the most common accident types, representing 31\%, 22\%, and 20\% of nonfatal accidents, respectively. Comparatively, in accident reports from OSHA regarding non-fatal cases, falls (37\%), exposure to electricity (36\%), and contact with objects $(19 \%)$ caused most of the injuries. Putting aside "transportation incidents" (19\%), the main three events for fatal accidents in BLS data were "exposure to harmful substances and environments" (50\%), "falls" (21\%), and "contact with objects and equipment" (7\%). Among fatal cases of OSHA reports, exposure to electricity is also the leading event, causing exactly the same $50 \%$ of deaths followed by falls $(28 \%)$ and contact with objects $(19 \%)$. The order and magnitude of accident types are very similar in both studies especially in fatal cases. The share of exposure to electricity in fatal cases is much lower for the entire construction industry $(18 \%$ in BLS data) which can be attributable to a much wider range of work categories in the industry compared to a more limited activities among specialty trades such as electrical contractors. This finding further emphasizes on the necessity of investigating accidents within a specific trade, since focusing one particular type of accident (e.g., exposure to electricity) can reduce the number of fatalities/severe injuries dramatically. For electrical contractors this means more electrical training on main sources and causes of exposures to electricity and ultimately decrease the more severe injuries presented in OSHA's data.

By using these findings from exploratory data analysis, one can start to decipher some of the more common accident scenarios among electrical workers. For instance, electrocutions and burns to body system and upper extremities often happened historically in exposure to electricity accidents wherein 
parts and material are the source of injury and small, new, nonresidential buildings are the location of accident. Though they used different methods, some studies have similarly examined the associations linking accident factors [46-48]. For instance, Chi et al. [47] investigated fatal fall accidents to demonstrate how different types of falls are linked to specific causes; the team then suggested several prevention measures based on strong links between a cause and its consequent accident. Chi et al. [48] also found that the source and cause of injury are significant factors in classifying accident scenarios. While our study does not present our analysis as identifying the permutations of factors that predict accidents-indeed, such a goal is outside our scope-the analysis we present here highlights where future efforts to investigate accident scenarios quantitatively (e.g., clustering, predictive modeling) would benefit the industry.

Furthermore, industry would benefit from studying the effect of different factors in fatal scenarios more. According to OSHA reports, and as we describe above, $37 \%$ of all catastrophic accidents that occurred to electrical contractors between 2007 to 2013 were fatal. Our investigation suggests when the project type is demolition, project budget is between $\$ 5$ million to $\$ 20$ million, sources of injury is vehicles or machinery, causes of injury is fencing, installing lights and signs, or installing plumbing and lighting fixtures, or temporary work, event type is exposure to electricity, injury type is electrocutions or concussions, and body part is body system or head, there is a higher chance that an accident lead to a fatality (i.e., at least $5 \%$ more than the average fatality rate of $37 \%$ ). Also, human factors-such as malfunctioned lockout/tagout procedures and inappropriate position for task-and environmental factors-such as material-handling equipment/method, overhead moving-/falling-object action, and squeeze-point action - have contributed to fatalities at larger rates. When planning for injury prevention practices, existence of any of these factors could raise a red flag and consequently, safety managers can design customized interventions to reduce severity and frequency of incidents among electrical contractors. Other than their exploratory values in showing more hazardous situations for electrical contractors, these findings propose that the degree of injury might be affected significantly by some factors that are related to a project's characteristic or a worker's task.

To examine these potential associations, the research team applied chi-square independence test and found that, except for the project end-use and cost, six accident factors have significant influence on the degree of an injury (Table 6). Ordered by their Cramer's V values, nature of injury and part of body correlate with the degree of injury most, followed by source of injury, project type, event type, and cause of injury. Considering the effects of a single nature of injury on the degree of injury, this study has found that electrocutions and concussions are associated with more fatal injuries. Regarding injured parts of body, this study found that, among electrical workers, injuries that affect the body system result in fatalities at a greater rate than even injuries to head. Investigating accident scenarios that lead to such body-part specific injuries (e.g., electrocutions that affect the body system or head concussions) should be prioritized in future studies. Similar conclusions, with a lower level of certainty, can be made about other factors such as source of injury and event type. Thus, knowing that a factor (e.g., a specific source of injury) might lead to a fatality more often than another provides empirical evidence for planning decisions that would impact safety of workers on construction sites.

\section{Conclusions}

Electrical contractors working in the construction industry are exposed to various hazardous situations leading to high numbers of severe injuries and fatalities [24,27]. Despite its importance, little has been understood regarding the contributing factors to occupational accident occurrence for small electrical contracting enterprises. To address this knowledge gap, the main objective of the present work is to study the individual effect of different contributing factors (e.g., project characteristics, sources, and causes of injury) on the degree of an injury. Our findings reveal that six factors have significant effects on fatality rates, with nature of injury and injured part of body having the highest association. Safety managers can benefit from these findings to better allocate their limited safety resources and develop personalize interventions (e.g., trainings) to mitigate safety risks. One can conclude that protecting body system from electric shocks and protecting head from concussions could be effective ways to reduce occupational fatality rates among electrical workers. Investigating 
the combined impacts of accident factors on the degree of injury requires applying other multivariate statistical approaches such as logistic regression models which is not in the scope of this study.

Outside of these practical implications, this study also contributes to the body of knowledge by proposing a content-analysis framework based on classification standards. The effectiveness of any safety recommendations, that is based on historical data, is only as good as the quality of the data (i.e., accident reports). The second objective of this study was accomplished by investigating the quality of data from one of the major data sources for occupational safety studies in the United States. Four main limitations were reported and discussed in the study solutions were suggested to overcome each limitation. This process can clarify accident mechanisms by providing consistency among accident factors and by redefining ambiguous situations. This data-preparation procedure can provide a common understanding of construction accidents and their consequences among safety researchers and practitioners, which facilitates communications among these parties.

This work discusses several contributing factors to analyze accidents that occur to electrical contractors and provides insight for current and future consideration. In particular, future studies can incorporate other important general variables, such as age and sex of the employee, time of the accident, more specific information on the specific type of accidents (e.g., height for fall accidents, and voltage for exposure-to-electricity cases). The severity of accidents also can be defined more accurately by considering more variables such as monetary cost of injuries or days away from work for non-fatal incidents. Continuing research in this filed will enable safety managers to develop personalize interventions to further reduce severity and frequency of incidents among electrical contractors.

Author Contributions: All authors contributed to the idea and concept of this study

Funding: This research was funded by CPWR - The Center for Construction Research and Training - through cooperative agreement number U60-OH009762 from the National Institute of Occupational Safety and Health (NIOSH). Its contents are solely the responsibility of the authors and do not necessarily represent the official views of the CPWR or NIOSH.

Conflicts of Interest: The authors declare no conflict of interest.

\section{References}

1. Abudayyeh, O., Federicks, T., Palmquist, M., and Torres, H. N. Analysis of occupational injuries and fatalities in electrical contracting industry. Journal of Construction Engineering and Management, 129(2), 2003, 152-158.

2. Esmaeili, B., and Hallowell, M. R. Diffusion of Safety Innovations in the Construction Industry. ASCE, Journal of Construction Engineering and Management, 138(8), 2012, 955-963.

3. Sousa, V., Almeida, N. M., and Dias, L. A. Risk-based management of occupational safety and health in the construction industry-Part 1: Background knowledge. Safety Science, 2014, 66, 75-86.

4. Chen, G. X., and Fosbroke, D. E. Work-related fatal-injury risk of construction workers by occupation and cause of death. Human and Ecological Risk Assessment, 4(6), 1998, 1371-1390.

5. Robinson, C. F., Petersen, M., and Palu, S. Mortality patterns among electrical workers employed in the US construction industry, 1982-1987. American Journal of Industrial Medicine, 36(6), 1999, 630-637.

6. Bureau of Labor Statistics. (2018). Census of fatal occupational injuries. < https://www.bls.gov/iif/oshcfoil.htm> , (March 12, 2019)

7. Fordyce, T. A., Kelsh, M., Lu, E. T., Sahl, J. D., and Yager, J. W. Thermal burn and electrical injuries among electric utility workers, 1995-2004. Burns, 33(2), 2007, 209-220.

8. Fordyce, T. A., Morimoto, L., Coalson, J., Kelsh, M. A., and Mezei, G. Neck injuries among electric utility workers, 1995-2007. Journal of Occupational and Environmental Medicine, 52(4), 2010, 441-449.

9. Fordyce, T. A., Leonhard, M. J., Watson, H. N., Mezei, G., Vergara, X. P., and Krishen, L. An analysis of fatal and non-fatal injuries and injury severity factors among electric power industry workers. American Journal of Industrial Medicine, 59(11), 2016, 948-958.

10. Volberg, V., Fordyce, T., Leonhard, M., Mezei, G., Vergara, X., and Krishen, L. Injuries among electric power industry workers, 1995-2013." Journal of Safety Research, 60, 2017, 9-16. 
11. Ore, T., and Casini, V. Electrical fatalities among US construction workers. Journal of Occupational and Environmental Medicine, 38(6), 1996, 587-592.

12. Kisner, S., and Casini, V. Epidemiology of electrocution fatalities: 1998. In Worker Deaths by Electrocution: A Summary of NIOSH Surveillance and Investigative Findings., Department of Health and Human Services (NIOSH), May 1998, pp 9-19. Publication No. 98-131, Washington, DC.

13. Loomis, D., Dufort, V., Kleckner, R. C., and Savitz, D. A. Fatal occupational injuries among electric power company workers. American Journal of Industrial Medicine, 35(3), 1999, 302-309.

14. Robinson, C. F., Petersen, M., and Palu, S. Mortality patterns among electrical workers employed in the US construction industry, 1982-1987. American Journal of Industrial Medicine, 36(6), 1999, 630-637.

15. Taylor, A. J., McGwin, G., Valent, F., and Rue, L. W. Fatal occupational electrocutions in the United States. Injury Prevention, 8(4), 2002, 306-312.

16. McCann, M., Hunting, K. L., Murawski, J., Chowdhury, R., and Welch, L. Causes of electrical deaths and injuries among construction workers. American Journal of Industrial Medicine, 43(4), 2003, 398-406.

17. Janicak, C. A. Occupational fatalities due to electrocutions in the construction industry." Journal of Safety Research, 39(6), 2008, 617-621.

18. Homce, G. T., Cawley, J. C, \& Yenchek, M. R. A performance evaluation of two overhead power line proximity warning devices (Information Circular 9510. DHHS (NIOSH) Publication No. 2009-110, 2008). Atlanta, GA: National Institute for Occupational Safety and Health.

19. Jenkins, E. L., Kisner, S. M., Fosbroke, D. E., Layne, L. A., Stout, N. A., Castillo, D. N., Cutlip, C. P., and Cianfrocco, R., Fatal injuries to workers in the United States, 1980-1989; a decade of surveillance: national profile. National Institute for Occupational Safety and Health, Cincinnati, OH, 1993.

20. Cawley, J. C., and Homce, G. T. Trends in electrical injury, 1992-2002. IEEE Transactions on Industry Applications, 44(4), 2008, 962-972

21. Chi, C. F., Yang, C. C., and Chen, Z. L. In-depth accident analysis of electrical fatalities in the construction industry. International Journal of Industrial Ergonomics, 39(4), 2009, 635-644.

22. Hesla, E. Improvements in safe working practices near overhead lines. In Conference Record 2009 IEEE Industrial \& Commercial Power Systems Technical Conference (pp. 1-5). 2009, IEEE.

23. Neitzel, R. L., Seixas, N. S., and Ren, K. K. A review of crane safety in the construction industry. Applied Occupational and Environmental Hygiene, 16(12), 2001, 1106-1117.

24. Gholizadeh, P., and Esmaeili, B. Electrical Contractors' Safety Risk Management: An Attribute-Based Analysis. ASCE International Workshop on Computing in Civil Engineering, Austin, TX, June 21-23, 2015.

25. Esmaeili, B., Hallowell, M. R., Rajagopalan, B. Attribute-Based Safety Risk Assessment I: Analysis at the Fundamental Level. ASCE, Journal of Construction Engineering and Management, 141(8), 2015a, 04015021.

26. Esmaeili, B., Hallowell, M. R., Rajagopalan, B. Attribute-Based Safety Risk Assessment II: Predicting Safety Outcomes Using Generalized Linear Models. ASCE, Journal of Construction Engineering and Management, 141(8), 2015b, 04015022.

27. Gholizadeh, P., and Esmaeili, B. Applying Classification Trees to Analyze Electrical Contractors' Accidents. Construction Research Congress (CRC 2016), Puerto Rico, May 31-June 2, 2016.

28. Gholizadeh, P., Esmaeili, B., and Memarian, B. Evaluating the Performance of Machine Learning Algorithms on Construction Accidents: An Application of ROC Curves. Construction Research Congress (CRC 2018), ASCE, New Orleans, Louisiana, 2018.

29. Hinze, J., and Russell, D. B. Analysis of fatalities recorded by OSHA. Journal of Construction Engineering and Management, 121(2), 1995, 209-214.

30. Hinze, J., Pedersen, C., and Fredley, J. Identifying root causes of construction injuries. Journal of Construction Engineering and Management, 124(1), 1998, 67-71.

31. Kang, Y., Siddiqui, S., Suk, S. J., Chi, S., and Kim, C. Trends of fall accidents in the US construction industry. Journal of Construction Engineering and Management, 143(8), 2017, 04017043.

32. Bureau of Labor Statistics. Occupational Injury and Illness Classification Manual (OIICM). 2012. < https://www.bls.gov/iif/oiics manual 2010.pdf>, (March 5, 2019)

33. Office of Management and Budget. North American Industry Classification System, 2017, < https://www.census.gov/eos/www/naics/2017NAICS/2017 NAICS Manual.pdf>, (March 3, 2019)

34. McHugh, M. L. The chi-square test of independence. Biochemia Medica: Biochemia Medica, 23(2), 2013, 143-149. 
35. Sharpe, D. Your chi-square test is statistically significant: now what? Practical Assessment, Research $\mathcal{E}$ Evaluation, 20, 2015.

36. Bakker, M., and Wicherts, J. M. The (mis) reporting of statistical results in psychology journals. Behavior Research Methods, 43(3), 2011, 666-678.

37. Mustapha, F. H., and Naoum, S. Factors influencing the effectiveness of construction site managers. International Journal of Project Management, 16(1), 1998, 1-8.

38. Zuppa, D., Issa, R. R., and Suermann, P. C. BIM's impact on the success measures of construction projects. Computing in Civil Engineering, 2009, 503-512.

39. Fan, C., Oh, D. S., Wessels, L., Weigelt, B., Nuyten, D. S., Nobel, A. B., Van't Veer, L. J., and Perou, C. M. Concordance among gene-expression-based predictors for breast cancer. New England Journal of Medicine, 355(6), 2006, 560-569.

40. Cramér, H. Mathematical methods of statistics. 1946. Department of Mathematical SU.

41. Walker, H. M., and Lev, J. Statistical inference. 1953, Oxford and IBH Publishing Co.; Calcutta.

42. Lee, H. S., Kim, H., Park, M., Ai Lin Teo, E., and Lee, K. P. Construction risk assessment using site influence factors. Journal of Computing in Civil Engineering, 26(3), 2011, 319-330.

43. Kisner, S. M., and Fosbroke, D. E. Injury hazards in the construction industry. Journal of occupational medicine.: official publication of the Industrial Medical Association, 36(2), 1994, 137-143.

44. Kines, P., Spangenberg, S., and Dyreborg, J. Prioritizing occupational injury prevention in the construction industry: Injury severity or absence?. Journal of Safety Research, 38(1), 2007, 53-58.

45. Choi, S. D. Aging workers and trade-related injuries in the US construction industry. Safety and Health at Work, 6(2), 2015, 151-155.

46. Chi, C. F., Chang, T. C., and Hung, K. H. Significant industry-source of injury-accident type for occupational fatalities in Taiwan. International Journal of Industrial Ergonomics, 34(2), 2004, 77-91.

47. Chi, C. F., Chang, T. C., and Ting, H. I. Accident patterns and prevention measures for fatal occupational falls in the construction industry. Applied Ergonomics, 36(4), 2005, 391-400.

48. Chi, C. F., Lin, Y. Y., and Ikhwan, M. Flow diagram analysis of electrical fatalities in construction industry. Safety Science, 50(5), 2012, 1205-1214. 